\title{
Dielectric properties of binary polyvinylidene fluoride/barium titanate nanocomposites and their nanographite doped hybrids
}

\author{
Y. C. $L i^{1,2}$, S. C. Tjong ${ }^{1 *}$, R. K. Y. $L i^{1}$ \\ ${ }^{1}$ Department of Physics and Materials Science, City University of Hong Kong, Kowloon Town, Kowloon, Hong Kong \\ ${ }^{2}$ Department of Materials Science and Engineering, Liaocheng University, Shandong, China
}

Received 8 October 2010; accepted in revised form 26 December 2010

\begin{abstract}
Binary polyvinylidene fluoride/barium titanate $\left(\mathrm{PVDF} / \mathrm{BaTiO}_{3}\right)$ and its nanographite $(\mathrm{GN})$ doped ternary nanocomposites were fabricated using a simple solution casting process followed by compression molding. The dielectric behavior of such hybrids over a wide frequency range was studied. Additions of GN with contents close to the percolation threshold were found to be very effective to enhance dielectric permittivity of the $\mathrm{PVDF} / \mathrm{BaTiO}_{3}$ nanocomposites. In this regard, the electrical behavior of ternary $\mathrm{PVDF} / \mathrm{BaTiO}_{3} / \mathrm{GN}$ hybrids can be explained in terms of the percolation theory. Furthermore, both dielectric constant and electrical conductivity of hybrids were found to be strongly frequency and temperature dependent.
\end{abstract}

Keywords: nanocomposites, electrical properties, dielectric constant, graphite nanosheet

\section{Introduction}

Ferroelectrics such as barium titanate $\left(\mathrm{BaTiO}_{3}\right)$, lead titanate $\left(\mathrm{PbTiO}_{3}\right)$ and lead zirconium titanate (PZT) with the perovskite crystal structure have gained considerable interest in industrial sectors. Ferroelectric ceramics exhibit excellent dielectric properties but poor mechanical performances. On the other hand, polymers possess good flexibility but low dielectric permittivity. Thus, combination ferroelectric fillers and polymer can overcome these deficiencies. Despite the advantages of being well processable, inexpensive and low dielectric loss, the dielectric constant of 0-3 composites remains unsatisfactory. For example, Venkatragavaraj et al. [1] incorporated PZT of high permittivity $\left(\varepsilon^{\prime}=\right.$ $1750)$ into polyvinylidene fluoride (PVDF) $\left(\varepsilon^{\prime}=\right.$ 12) using both solution-mixing and melt-blending processes. They found that the dielectric constant of resulting composites at room temperature is below 100 even at $50 \%$ filler loading. Such composites are ineffective to be used as materials for capacitors and transducers.

The dielectric properties of polymer- $\mathrm{BaTiO}_{3}$ composites depend on several factors including the size and filler content as well as the interfacial bonding between the filler and polymer matrix [1-4]. In general, the dielectric permittivity of barium titanate degrades markedly when its grain size reduces from the micrometer down to nanometer level. A transition from tetragonal to cubic crystal structure occurs by refining its grain size to the nanometer regime [4]. The cubic phase of barium titanate exhibits low permittivity. In a recent study, Xie et al. [5] demonstrated that the addition of $50 \mathrm{vol} \% \mathrm{BaTiO}_{3}$ nanoparticles $(100 \mathrm{~nm})$ to polyimide only yield a dielectric constant of 35 .

\footnotetext{
${ }^{*}$ Corresponding author, e-mail: aptjong@cityu.edu.hk
}

(c) BME-PT 
According to the literature, the dielectric constant of polymers filled with $\mathrm{BaTiO}_{3}$ microparticles can be enhanced greatly by adding conducting metal and carbon black microparticles as well as vapor grown carbon fibers [6-8]. A significant rise in dielectric constant of such three-component $0-3$ composites occurs near the percolation threshold. This is due to the formation of a large quantity of minicapacitors. The conducting fillers are in very close proximity to one another, but remain insulated by thin polymer surface layers. In this respect, conducting nanoparticles are anticipated to be more effective than their microparticle fillers to increase the permittivity of polymer composites.

Graphite is a polymorphic form of carbon consisting of graphene layers stacked along its long crystal axis. Sulfuric acid intercalant is incorporated into graphite interlayers, forming the so-called graphite intercalation compound (GIC). GIC is then subjected to rapid heating or thermal shock to release the intercalant, leading to the formation of expanded graphite (EG). The EG can be further exfoliated into graphite nanosheets of large aspect ratios under sonication. It is considered that graphite nanosheet additions are also beneficial in enhancing dielectric permittivity of $\mathrm{PVDF} / \mathrm{BaTiO}_{3}$ nanocomposites. In this study, binary $\mathrm{PVDF} / \mathrm{BaTiO}_{3}$ and ternary graphite nanosheet doped $\mathrm{PVDF} / \mathrm{BaTiO}_{3}$ nanocomposites were fabricated via solution mixing followed by compression molding. The purpose is to investigate the electrical responses of polymer composites filled with both conducting graphite nanosheets and insulating $\mathrm{BaTiO}_{3}$ nanofillers.

\section{Experimental}

\subsection{Materials}

PVDF resin (Kynar 740) with a density of $1.78 \mathrm{~g} / \mathrm{cm}^{3}$ was supplied by Atofina Chemicals Inc. (Philadelphia, Pennsylvania, USA). Spherical barium titanate nanoparticles $(85-128 \mathrm{~nm})$ with density of $5.85 \mathrm{~g} / \mathrm{cm}^{3}$ were purchased from Nanostructured \& Amorphous Materials Inc. (Houston, Texas, USA). Graphite nanosheet (GN) was supplied by Institute of Polymer and Nanomaterials, Huaqiao University (Quanzhou, China) [9]. The detailed fabrication method of GN was briefly described herein. Natural graphite flake with an average diameter of $500 \mu \mathrm{m}$ was treated with concentrated sulfuric acid and fuming nitric acid $(4: 1, \mathrm{v} / \mathrm{v})$ for several hours to produce GIC. Then, the resulting GIC was subjected to a thermal shock at $\sim 1000^{\circ} \mathrm{C}$ in a furnace to yield EG. Finally, EG was exfoliated into GN in an alcohol-based solvent under sonication for several hours. The resulting GNs with a large aspect ratio of $\sim 250$ were collected and used in this study.

\subsection{Fabrication of nanocomposites}

PVDF was dissolved initially in a flask containing $15 \mathrm{wt} \% \mathrm{~N}, \mathrm{~N}$-dimethylformamide (DMF) solvent. Barium titanate nanofillers of $10-60 \mathrm{wt} \%$ were then added to the mixed solution for fabricating PVDF/ $\mathrm{BaTiO}_{3}$ nanocomposites. To prepare three-component hybrid nanocomposites, the weight ratio of $\mathrm{PVDF} / \mathrm{BaTiO}_{3}$ was kept at $80 / 20$. Graphite nanosheet of 1 to $4 \mathrm{phr}$ was also added independently to the precursor solution. The nanocomposite solution was sonicated for $10 \mathrm{~h}$ and then heated at $70^{\circ} \mathrm{C}$ for solvent removal. The resulting products were dried and compression-molded at $220^{\circ} \mathrm{C}$ for $10 \mathrm{~min}$.

\subsection{Structural and electrical measurements}

The microstructure of composites was observed in a scanning electron microscope (SEM, JEOL JSM820, JEOL, Tokyo, Japan). A thin gold layer was sputter-coated onto the composite specimens prior to SEM observation. X-ray diffraction (XRD) measurements were performed using a Philip X'pert diffractometer (PANalytical, Almelo, The Netherlands) in the $2 \theta$ range of $2-50^{\circ}$ at a scanning speed of $3 \% \mathrm{~min}$. Disk specimens for electrical measurements were coated with a silver paste. The frequency dependent electrical properties were measured with an impedance analyzer (Agilent model 4294 A, Agilent, Santa Clara, California, USA) at room temperature. Therefore, a complex permittivity of the composites can be obtained: $\varepsilon^{*}=\varepsilon^{\prime}-j \varepsilon^{\prime \prime}$, where $\varepsilon^{\prime}$ is the real part of permittivity and $\varepsilon^{\prime \prime}$ is the dielectric loss. The impedance analyzer was equipped with a small furnace for measuring temperature dependent electrical properties. The heating rate of the furnace was maintained at $5^{\circ} \mathrm{C} / \mathrm{min}$.

\section{Results and discussion \\ 3.1. Dielectric responses of $\mathrm{PVDF} / \mathrm{BaTiO}_{3}$ composites}

Figure 1 shows the variation of $\varepsilon^{\prime}$ with $\mathrm{BaTiO}_{3}$ content for the $\mathrm{PVDF} / \mathrm{BaTiO}_{3}$ nanocomposites tested at a frequency of $1 \mathrm{kHz}$. It can be seen that the $\varepsilon^{\prime}$ 


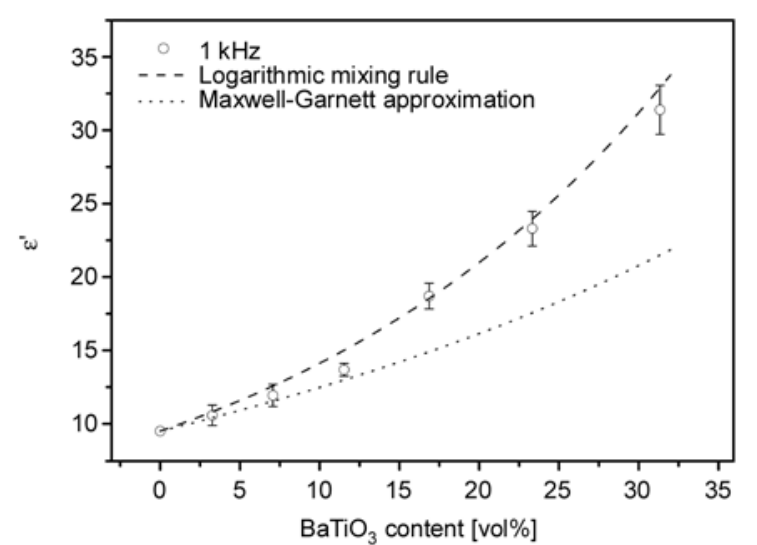

Figure 1. Dielectric constant vs $\mathrm{BaTiO}_{3}$ contents for $\mathrm{PVDF} / \mathrm{BaTiO}_{3}$ nanocomposites

increases with increasing filler content. At $31.5 \mathrm{vol} \%$ $\mathrm{BaTiO}_{3}, \varepsilon^{\prime}$ value reaches to 31.4 , being $\sim 3.5$ times higher than that of neat PVDF. Theoretically, the dielectric responses of ceramic-polymer systems can be described by the logarithmic mixing rule and Maxwell-Garnett approximation [6, 10, 11]. Logarithmic mixing rule simply relates the permittivity of a composite to a combined dielectric effect of its individual constituents, see Equation (1):

$\log \varepsilon_{\mathrm{c}}{ }^{\prime}=x \log \varepsilon_{\mathrm{f}}{ }^{\prime}+(1-x) \log \varepsilon_{\mathrm{p}}{ }^{\prime}$

Maxwell-Garnett approximation is applicable to the inclusions embedded in a continuum matrix of the polymer composite. Mathematically, the permittivity can be expressed by Eqution (2):

$\varepsilon_{\mathrm{c}}{ }^{\prime}=\varepsilon_{\mathrm{p}}{ }^{\prime}\left(1+\frac{3 x A}{1-x A}\right)$

where $A=\left(\varepsilon_{\mathrm{f}}{ }^{\prime}-\varepsilon_{\mathrm{p}}{ }^{\prime}\right) /\left(\varepsilon_{\mathrm{f}}{ }^{\prime}+2 \varepsilon_{\mathrm{p}}{ }^{\prime}\right), x$ denotes the volume fraction of $\mathrm{BaTiO}_{3}$ filler, $\varepsilon_{\mathrm{c}}{ }^{\prime}, \varepsilon_{\mathrm{f}}{ }^{\prime}, \varepsilon_{\mathrm{p}}{ }^{\prime}$ denote the real part permittivity of the composite, $\mathrm{BaTiO}_{3}$ and PVDF, respectively. Using $\varepsilon_{\mathrm{f}}{ }^{\prime}=500, \varepsilon_{\mathrm{p}}{ }^{\prime}=9.5$ and $f=1 \mathrm{kHz}$, Equation (1) and (2) are plotted as dash and dot curves respectively as shown in Figure 1. It is evident that the experimental data points obey the logarithmic mixing rule at high filler content while follow the Maxwell-Garnett approximation at low filler content.

Figure $2 \mathrm{a}-\mathrm{b}$ shows the respective plots of $\varepsilon^{\prime}$ and $\tan \delta$ vs frequency for the $\mathrm{PVDF} / \mathrm{BaTiO}_{3}$ nanocomposites. There exists a distinct enhancement in dielectric constant with increasing filler content while the loss tangent remains nearly the same. The $\varepsilon^{\prime}$ values of nanocomposites decrease with increasing frequency. A significant drop in $\varepsilon^{\prime}$ occurs when

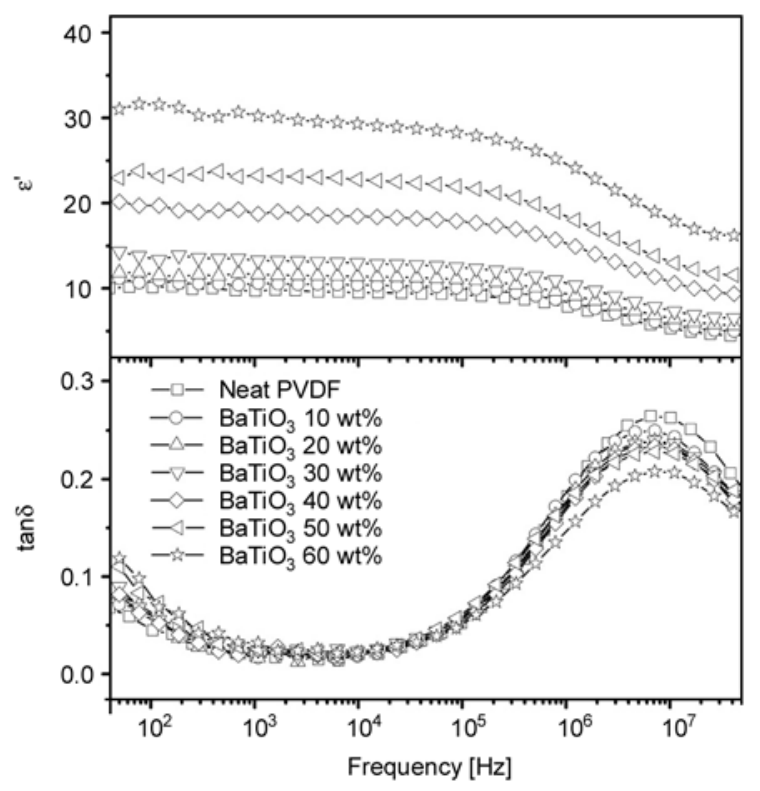

Figure 2. (a) Dielectric constant and (b) loss tangent as a function of frequency for PVDF and PVDF/ $\mathrm{BaTiO}_{3}$ nanocomposites

the frequency reaches to $3 \cdot 10^{5} \mathrm{~Hz}$. This is attributed to the dipole relaxation of the composites lags behind the fast change of applied fields. In this regime, characteristic relaxation peaks of PVDF matrix can be observed (Figure 2b).

Figure $3 \mathrm{a}-\mathrm{b}$ shows SEM images of the PVDF/ $\mathrm{BaTiO}_{3}$ 80/20 and $\mathrm{PVDF} / \mathrm{BaTiO}_{3}$ 50/50 nanocomposites. Barium titanate nanoparticles are found to disperse homogeneously in the matrix of nanocomposites prepared by means of solution mixing. A representative SEM image for the $\mathrm{GN} / \mathrm{BaTiO}_{3} /$ PVDF 2.5/20/80 hybrid is shown in Figure 4.

Figure 5 shows XRD patterns of $\mathrm{PVDF}, \mathrm{BaTiO}_{3}$, $\mathrm{PVDF} / \mathrm{BaTiO}_{3} \quad 80 / 20$ and $\mathrm{PVDF} / \mathrm{BaTiO} / \mathrm{GN}$ $80 / 20 / 2.5$ nanocomposites. The peaks located at $2 \theta=$ 18.5 and $20^{\circ}$ are characteristic reflections of $\alpha-$ PVDF. A distinct peak at $2 \theta=26.6^{\circ}$ is assigned to the (002) graphite characteristic reflection for the $\mathrm{PVDF} / \mathrm{BaTiO} 3 / \mathrm{GN}$ 80/20/2.5 nanocomposite. Barium titanate exhibits several diffraction peaks in the tested two-theta range. The peak at $2 \theta=45^{\circ}$ clearly indicates the presence of cubic barium titanate.

As recognized, $\mathrm{PVDF} / \mathrm{BaTiO}_{3}$ composites filled with $\mathrm{BaTiO}_{3}$ microparticles are well studied ceramic/ polymer composite materials due to their high dielectric constant [12]. This is because $\mathrm{BaTiO}_{3}$ microparticles with a tetragonal structure exhibit high permittivity. By refining the grain size of $\mathrm{BaTiO}_{3}$ down to nanometer regime, its permittivity 


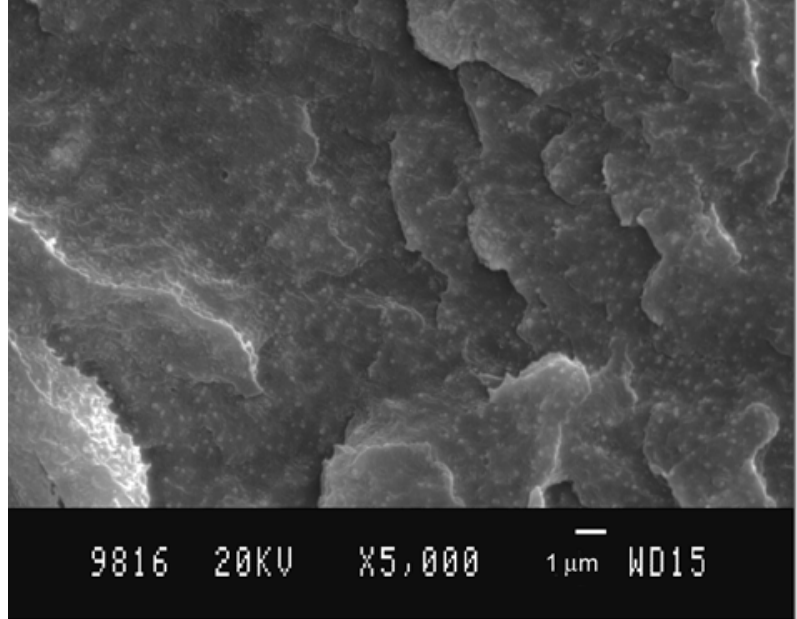

a)

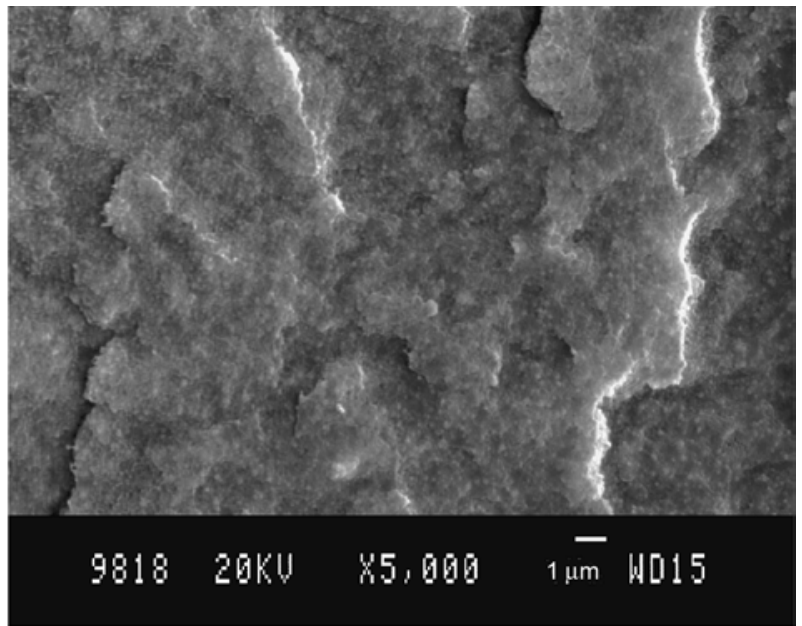

b)

Figure 3. SEM micrographs of (a) $\mathrm{PVDF} / \mathrm{BaTiO}_{3}$ 80/20 and (b) $\mathrm{PVDF} / \mathrm{BaTiO}_{3}$ 50/50 nanocomposites

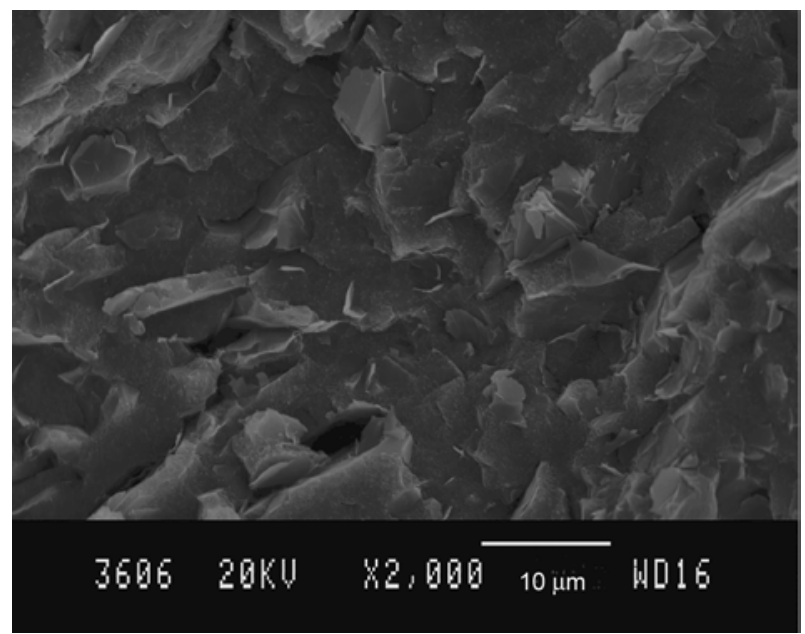

Figure 4. SEM image of $\mathrm{PVDF} / \mathrm{BaTiO}_{3} / \mathrm{GN}$ 80/20/2.5 hybrid

reduces significantly owing to a transition from tetragonal (ferroelectric) to cubic structure with a low dielectric constant. Therefore, $\mathrm{PVDF} / \mathrm{BaTiO}{ }_{3}$ nanocomposites require larger volume fractions of $\mathrm{BaTiO}_{3}$ nanoparticles to achieve a higher permittivity $[13,14]$. Table 1 lists the $\varepsilon^{\prime}$ and $\tan \delta$ values of neat $\mathrm{PVDF}$ and representative $\mathrm{PVDF} / \mathrm{BaTiO}_{3}$ nanocomposites. Apparently, it requires $60 \mathrm{wt} \% \mathrm{BaTiO}_{3}$ nanoparticle (31.5 vol\%) addition to PVDF to achieve a dielectric constant of 31.4. Very recently, Dou et al. [13] reported that $\mathrm{BaTiO}_{3} / \mathrm{PVDF}$ nanocomposite exhibits a dielectric constant of $\sim 29$ by adding $50 \mathrm{wt} \% \mathrm{BaTiO}_{3}$ nanoparticle. Similarly, the dielectric constant of polyester-styrene resin can be increased from 9.2 to 25.0 by adding heat treated $\mathrm{BaTiO}_{3}$ nanoparticle of $60 \mathrm{wt} \%$ (22 vol\%). Heat treatment was employed in order to induce grain

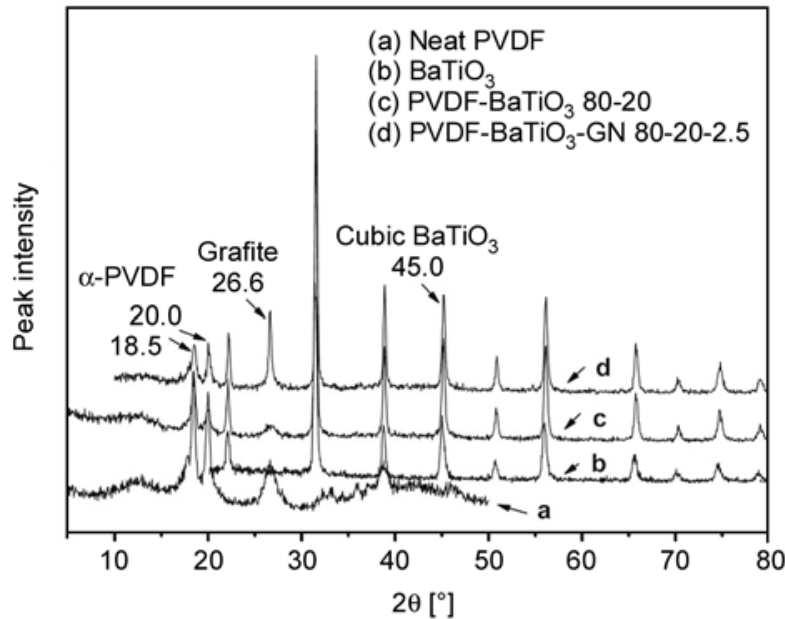

Figure 5. XRD patterns of (a) $\mathrm{PVDF}$, (b) $\mathrm{BaTiO}_{3}$, (c) $\mathrm{PVDF} /$ $\mathrm{BaTiO}_{3}$ 80/20 composite, and (d) $\mathrm{PVDF} / \mathrm{BaTiO}_{3} /$ GN 80/20/2.5 hybrid

Table 1. $\varepsilon^{\prime}$ and $\tan \delta$ values for neat PVDF and its nanocomposites determined at $1 \mathrm{kHz}$

\begin{tabular}{|l|r|c|}
\hline \multicolumn{1}{|c|}{ Specimen } & $\boldsymbol{\varepsilon}^{\prime}$ & $\tan \boldsymbol{\delta}$ \\
\hline Neat $\mathrm{PVDF}$ & 9.7 & 0.018 \\
\hline $\mathrm{PVDF} / \mathrm{BaTiO}_{3} 80 / 20$ & 11.6 & 0.019 \\
\hline $\mathrm{PVDF} / \mathrm{BaTiO}_{3} 40 / 60$ & 31.4 & 0.026 \\
\hline $\mathrm{PVDF} / \mathrm{BaTiO}_{3} / \mathrm{GN} 80 / 20 / 2.5$ & 50.0 & 0.072 \\
\hline $\mathrm{PVDF} / \mathrm{BaTiO}_{3} / \mathrm{GN} 80 / 20 / 3$ & 492.0 & 49.1 \\
\hline
\end{tabular}

and particle growth as well as lattice relaxation of $\mathrm{BaTiO}_{3}$ nanoparticles [15]. It appears that thermal treatment of $\mathrm{BaTiO}_{3}$ nanoparticles has little effect in achieving large permittivity for the polymer nanocomposites. In this respect, we employed GN as a third component or hybrid filler to further enhance the permittivity of binary $\mathrm{PVDF} / \mathrm{BaTiO}_{3}$ nanocomposites. 


\subsection{Electrical performance of GN/BaTiO 3 /PVDF hybrids}

Figure 6a shows dielectric responses of the PVDF/ $\mathrm{BaTiO}_{3} / \mathrm{GN}$ hybrids filled with low GN loading levels. Both the $\varepsilon^{\prime}$ and $\tan \delta$ values increase slowly with increasing GN content up to $2.5 \mathrm{phr}$. Thereafter, they increase sharply as the GN content approaches the percolation threshold. The $\mathrm{PVDF} / \mathrm{BaTiO}_{3} / \mathrm{GN}$ $80 / 20 / 2.5$ hybrid exhibits a large dielectric constant of 50 and low loss tangent of 0.072 at $1 \mathrm{kHz}$. The dielectric constant is four times larger than that of PVDF/BaTiO 3 80/20 nanocomposite ( 11.9). The $\mathrm{PVDF} / \mathrm{BaTiO}_{3} / \mathrm{GN}$ 80/20/2.5 hybrid also exhibits larger permittivity than the $\mathrm{PVDF} / \mathrm{BaTiO}_{3} 40 / 60$ system $\left(\varepsilon^{\prime}=31.4\right)$ as described above. In other words, $\mathrm{BaTiO}_{3}$ content of the composite can be reduced markedly from 60 to $20 \mathrm{wt} \%$ by adding only $2.5 \mathrm{phr}$ GN without sacrificing but rather improving the permittivity. The $\varepsilon^{\prime}$ and $\tan \delta$ values of $\mathrm{PVDF} / \mathrm{BaTiO}_{3} / \mathrm{GN}$ 80/20/2.5 and $\mathrm{PVDF} / \mathrm{BaTiO}_{3} /$ GN 80/20/3 hybrids are also listed in Table 1. An extremely large value of $\varepsilon^{\prime}=492$ can be achieved by adding $3 \mathrm{phr}$ GN loading. However, this hybrid is unsuitable for energy storage applications due to its extremely large dielectric loss resulting from the formation of GN network. The formation of conducting network enables trapped carriers to pass through readily, thereby dissipating stored energy considerably. A sharp transition from an insulator to

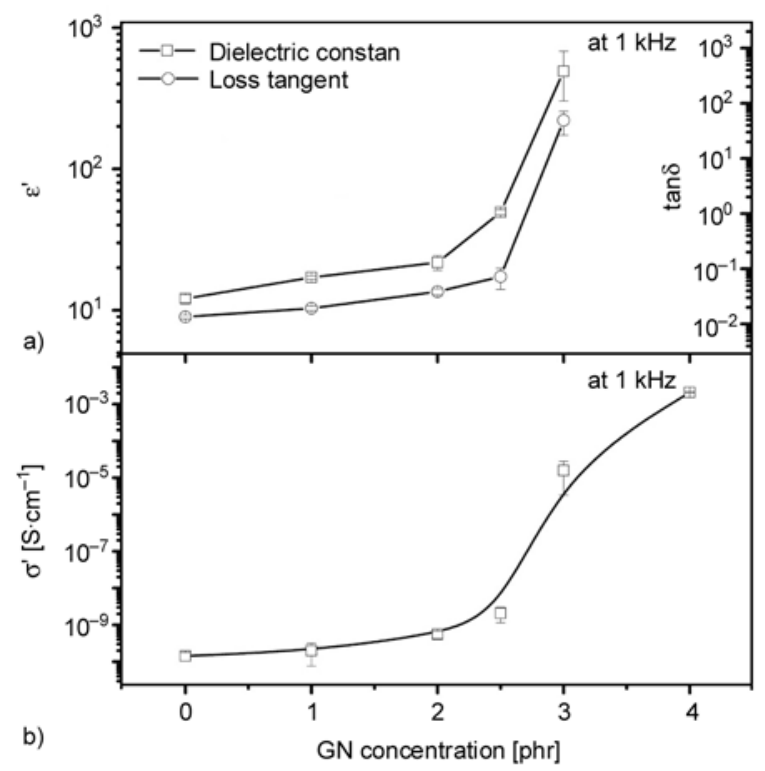

Figure 6. Variations of (a) dielectric constant and loss tangent, and (b) electrical conductivity with GN content for $\mathrm{PVDF} / \mathrm{BaTiO}_{3} / \mathrm{GN}$ hybrids conductor can be also seen from the plot of electrical conductivity vs GN content (Figure 6b).

In fact, large permittivity is beneficial for enhancing energy density stored in a capacitor as given by the expression: $\eta=\varepsilon \varepsilon_{0} E^{2} / 2$, where $\eta$ is the stored energy density, $\varepsilon$ the permittivity, and $\varepsilon_{0}$ the vacuum permittivity $\left(=8.85 \cdot 10^{-12} \mathrm{~F} \cdot \mathrm{m}^{-1}\right)$ and $E$ the applied field [16]. For instance, to generate an energy density of $0.1 \mathrm{~J} / \mathrm{cm}^{3}$, which is the value for the high performing piezoelectric ceramics, assuming a 50\% energy conversion efficiency, the electric field required is $47.5 \mathrm{MV} / \mathrm{m}$ for a capacitor with a dielectric constant of 10 (permittivity of pure PVDF). For the composite materials with higher permittivity, the lower electrical field is needed to reach a required energy density. Since the permittivity of $\mathrm{PVDF} / \mathrm{BaTiO}_{3} / \mathrm{GN} 80 / 20 / 2.5$ hybrid composite is 50 , an electrical field of only $21.3 \mathrm{MV} / \mathrm{m}$ is needed to satisfy an energy density of $0.1 \mathrm{~J} / \mathrm{cm}^{3}$.

Figure $7 \mathrm{a}-\mathrm{c}$ shows the frequency dependent dielectric constant, loss tangent and electrical conductivity of the $\mathrm{PVDF} / \mathrm{BaTiO}_{3} / \mathrm{GN}$ hybrids. It can be seen from Figure 7 a that the $\varepsilon^{\prime}$ value of hybrids decreases with increasing frequency. For hybrids with higher GN loadings, the variation of dielectric constant with frequency is even more apparent. The incorporation of a conducting graphite phase into the $\mathrm{PVDF} /$ $\mathrm{BaTiO}_{3}$ system affects its dielectric loss significantly, particularly at low frequency region (Figure $7 b$ ). The loss tangent increases dramatically by several orders of magnitude in the vicinity of percolation threshold, resulting from the formation of a conducting network. Figure $7 \mathrm{c}$ shows the variation of conductivity with frequency. The conductivity of hybrids with low GN contents increases linearly with frequency in a double logarithmic scale. Above the percolation threshold, a frequency independent conductivity or plateau predominates at the low frequency region. This is generally regarded as the dc conductivity. The electrical conductivity becomes frequency dependent when the frequency $(f)$ approaches a critical value $f_{\mathrm{c}}$ (at $\sigma=110 \% \sigma_{\mathrm{dc}}$ ). In general, 'ac universal' law (see Equation (3)) can be used to describe electrical conducting behavior of hybrids:

$\sigma_{\mathrm{ac}}{ }^{\prime}=\sigma_{\mathrm{dc}}+A \omega^{\mathrm{u}}$

where $\sigma_{\mathrm{ac}}{ }^{\prime}$, are $\sigma_{\mathrm{dc}}$ are the $a c$ and $d c$ conductivity of the composites, respectively; $A$ is a temperature 


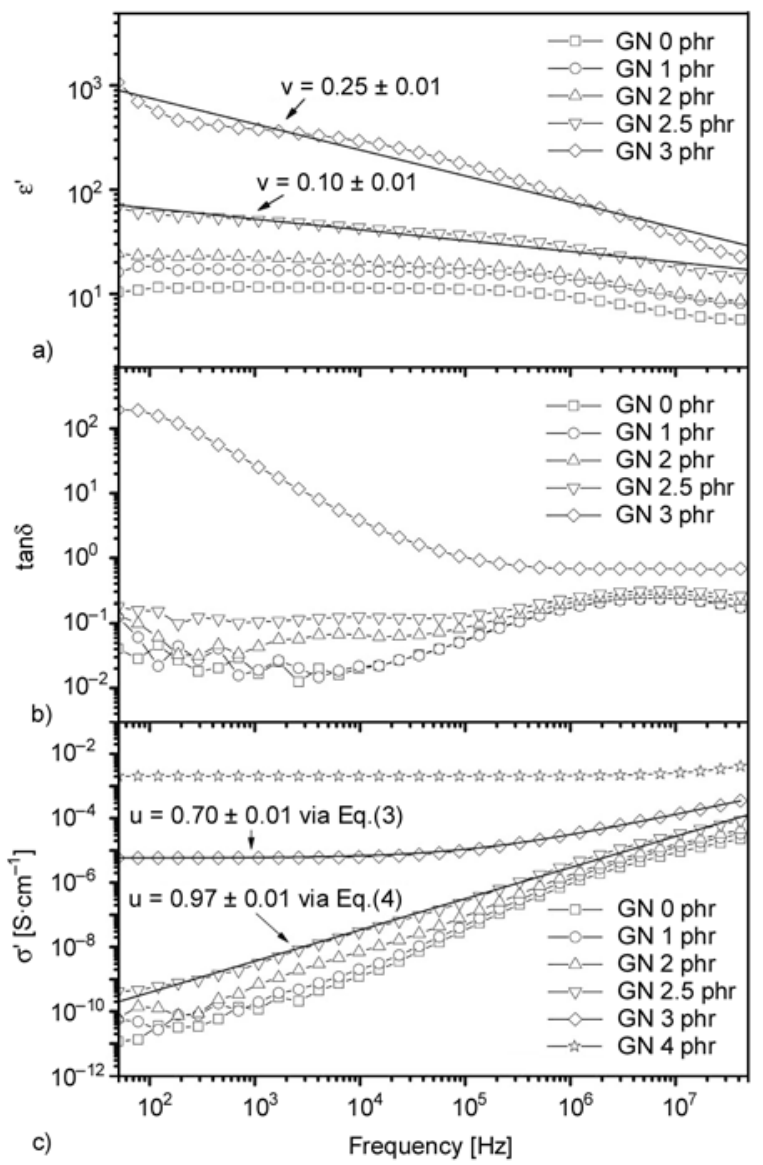

Figure 7. (a) Dielectric constant, (b) loss tangent and (c) conductivity as a function of frequency for PVDF/ $\mathrm{BaTiO}_{3} / \mathrm{GN}$ hybrids

dependant constant, $\mathrm{u}$ the critical exponent, and $\omega=$ $2 \pi f$. Below the percolation threshold, the $d c$ conductivity of composites is very small. Accordingly, the $\sigma_{\mathrm{dc}}$ term can be neglected and Equation (3) converts to: $\sigma_{\mathrm{ac}}{ }^{\prime}=A \omega^{\mathrm{u}}$. Therefore, ' $a c$ universal' law can predict the conducting behavior of composites with filler content above the percolation threshold more accurately. A representative fitting curve for the $\mathrm{PVDF} / \mathrm{BaTiO}_{3} / \mathrm{GN}$ 80/20/3 hybrid is shown in Figure 7c. A critical exponent $u=0.70$ is obtained accordingly.

The ac conductivity and dielectric constant of composites in the vicinity of the percolation threshold generally follow the power law relation [17], see Equations (4) and (5):

$\sigma^{\prime}\left(f, \phi_{\mathrm{c}}\right) \propto \omega^{\mathrm{u}}$

$\varepsilon^{\prime}\left(f, \phi_{\mathrm{c}}\right) \propto \omega^{-\mathrm{v}}$

where $v$ is a critical exponent that obeys the relation $u+v=1$. The $\sigma^{\prime}$ data of $\mathrm{PVDF} / \mathrm{BaTiO}_{3} / \mathrm{GN} 80 / 20 / 2.5$ and $\mathrm{PVDF} / \mathrm{BaTiO}_{3} / \mathrm{GN} 80 / 20 / 3$ hybrids can be best fitted using Equations (4) and (3) that prevail near and above the percolation threshold (Figure 7c). The $u$ values for $\mathrm{PVDF} / \mathrm{BaTiO}_{3} / \mathrm{GN} 80 / 20 / 2.5$ and $\mathrm{PVDF} / \mathrm{BaTiO}_{3} / \mathrm{GN} 80 / 20 / 3$ hybrids are 0.97 and 0.7 respectively. The fitting curves and $v$ values for dielectric constant of these two hybrids are shown in Figure 7a. The solid fitting curve for the PVDF/ $\mathrm{BaTiO}_{3} / \mathrm{GN}$ 80/20/3 hybrid using Equation (5) shows a slight deviation from experimental data. As mentioned above, Equation (5) prevails near the percolation threshold and the GN content of this composite is higher than the threshold. By reducing GN content to 2.5, the solid curve of $\mathrm{PVDF} / \mathrm{BaTiO}_{3} / \mathrm{GN}$ $80 / 20 / 2.5$ hybrid agrees reasonably with experimental data. The $u+v$ values for $\mathrm{PVDF} / \mathrm{BaTiO}_{3} / \mathrm{GN}$ 80/20/2.5 and $\mathrm{PVDF} / \mathrm{BaTiO}_{3} / \mathrm{GN}$ 80/20/3 hybrids are 1.07 and 0.95 , respectively, which obey closely the power law criterion.

\subsection{The effect of temperature}

Figure 8a shows temperature dependent dielectric constant of PVDF, PVDF/BaTiO 3 80/20 nanocomposite and their representative hybrids. For neat PVDF, the dielectric constant displays two distinct relaxation regions, showing transitions from low to high temperatures. These correspond to its $\beta$ - and $\alpha$ relaxation processes [18]. The $\alpha$-relaxation in this spectrum is associated with the molecular motion of

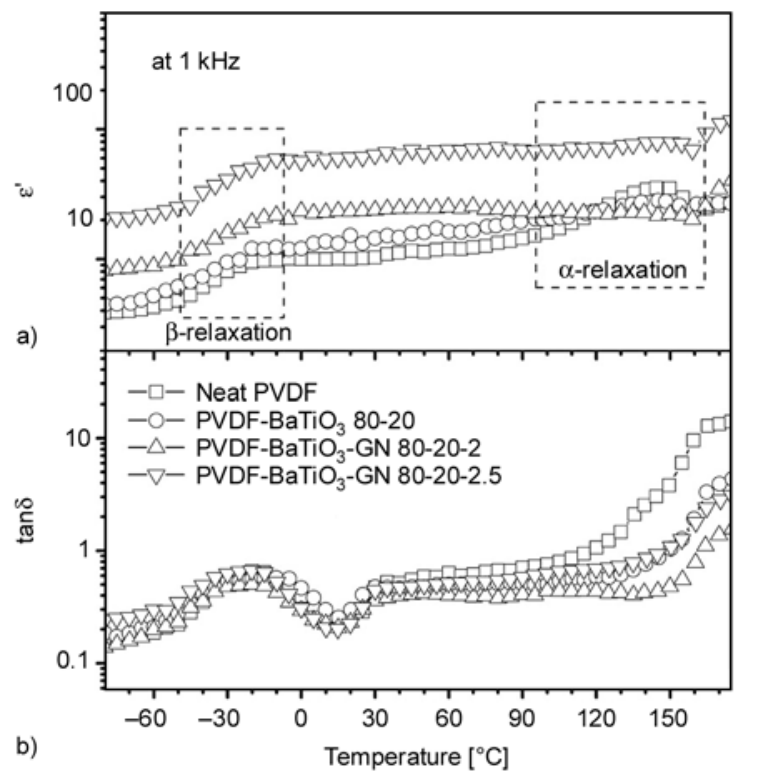

Figure 8. Dielectric constant and loss tangent vs temperature plots for PVDF, $\mathrm{PVDF} / \mathrm{BaTiO}_{3}$ 80/20 nanocomposite and their hybrids 

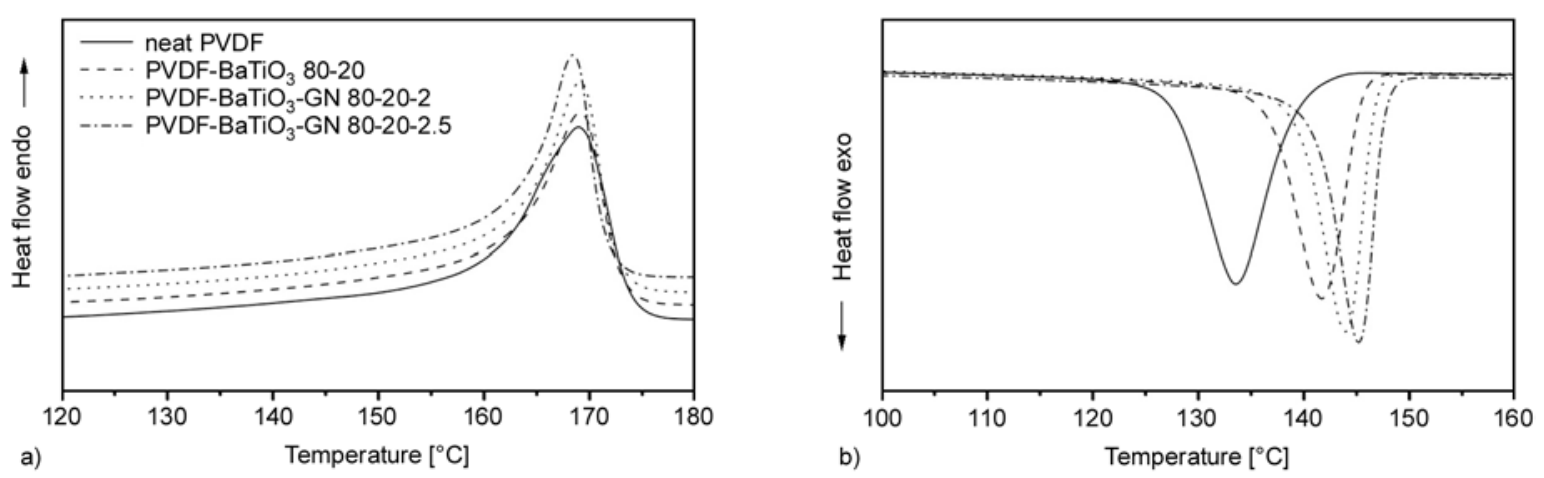

Figure 9. DSC (a) heating and (b) cooling curves for PVDF, $\mathrm{PVDF} / \mathrm{BaTiO}_{3}$ 80/20 nanocomposite and their hybrids

PVDF matrix near the melting temperature $\left(T_{\mathrm{m}}\right)$, while the $\beta$-relaxation is due to the segment movement of PVDF chains near $T_{\mathrm{g}}$. The effect of filler additions on these relaxations can be clearly seen in the plots of dielectric loss vs temperature (Figure $8 b$ ). The $\alpha$-relaxation peak intensity of the $\mathrm{PVDF} / \mathrm{BaTiO}_{3}$ 80/20 nanocomposite decreases by adding barium titanate.

Figure 9 shows DSC heating and cooling curves for $\mathrm{PVDF}, \mathrm{PVDF} / \mathrm{BaTiO}_{3}$ 80/20 nanocomposite and representative hybrids. These measurements were determined using a differential scanning calorimeter (Perkin model 2910) under a rate of $10^{\circ} \mathrm{C} / \mathrm{min}$ in a protected nitrogen atmosphere. The melting temperature of PVDF shows little changes by adding barium titanate and graphite nanosheet. However, a distinct increase in the crystallization temperature of PVDF is observed due to the nanofiller additions. This implies an effective nucleating effect of barium titanate and graphite nanosheet for the molecular chains of PVDF during the crystallization process.

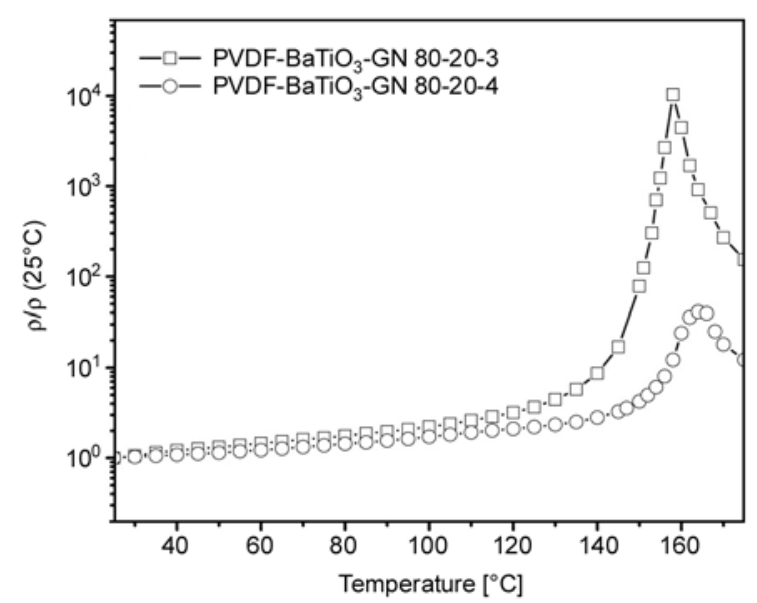

Figure10. Normalized resistivity vs temperature plots for $\mathrm{PVDF} / \mathrm{BaTiO}_{3} / \mathrm{GN}$ 80/20/3 and $\mathrm{PVDF} / \mathrm{BaTiO}_{3} /$ GN 80/20/4 hybrids

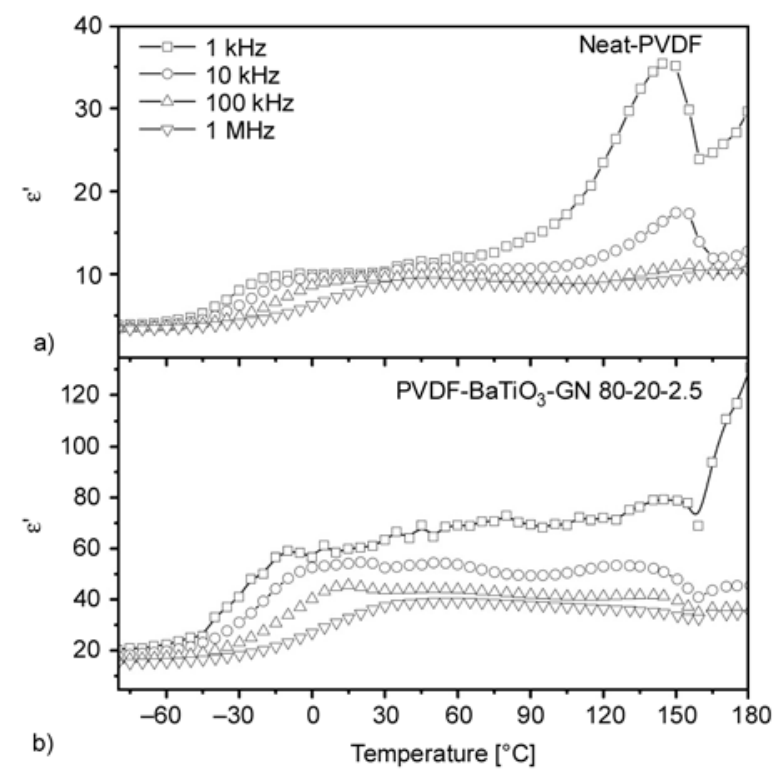

Figure 11. Variation of dielectric constant with temperature at different frequencies for (a) neat PVDF and (b) $\mathrm{PVDF} / \mathrm{BaTiO}_{3} / \mathrm{GN}$ 80/20/2.5 hybrid

The variation of resistivity (reciprocal of conductivity), normalized to that at $25^{\circ} \mathrm{C}$, with temperature of $\mathrm{PVDF} / \mathrm{BaTiO}_{3} / \mathrm{GN}$ 80/20/3 and $\mathrm{PVDF} / \mathrm{BaTiO}_{3} / \mathrm{GN}$ $80 / 20 / 4$ hybrids is shown in Figure 10. It is seen that the normalized resistivity of hybrids increases slowly with increasing temperature up to the vicinity of $T_{\mathrm{m}}$, follows by a sharp increase at $T_{\mathrm{m}}$. Such an increase in resistivity before $T_{\mathrm{m}}$ is commonly seen in many conducting polymers. This behavior is generally known as the positive temperature coefficient (PTC) effect that is mainly associated with thermal expansion of the polymer matrix. Moreover, the PTC peak intensity tends to decrease with increasing GN content. Due to the thermal expansion of polymer matrix, the distance between graphite nanosheets increases markedly. Thus, the interconnecting conduction paths within the polymer matrix are disturbed accordingly. 
Figure 11a-11b illustrates the change in $\varepsilon^{\prime}$ with temperature under different frequencies for neat $\mathrm{PVDF}$ and the $\mathrm{PVDF} / \mathrm{BaTiO}_{3} / \mathrm{GN} 80 / 20 / 2.5$ hybrid, respectively. It can be seen that the dielectric constant decreases with increasing frequency for both specimens. Furthermore, both the onset temperature of $\alpha$ - and $\beta$-relaxation peaks shifts to higher temperatures with increasing frequency.

\section{Conclusions}

In summary, binary $\mathrm{PVDF} / \mathrm{BaTiO}_{3}$ nanocomposites and ternary $\mathrm{PVDF} / \mathrm{BaTiO}_{3} / \mathrm{GN}$ hybrids were fabricated using solution mixing followed by compression molding. Electrical measurements showed that the real part of permittivity of $\mathrm{PVDF} / \mathrm{BaTiO}_{3}$ nanocomposites increases with increasing $\mathrm{BaTiO}_{3}$ content. Moreover, the incorporation of low loading levels of graphite nanosheets to the $\mathrm{PVDF} / \mathrm{BaTiO}{ }_{3}$ system led to a significant enhancement in dielectric permittivity, especially at the percolation threshold. The $\varepsilon^{\prime}$ value of the PVDF/BaTiO $3 / \mathrm{GN} 80 / 20 / 2.5$ hybrid was 50, being four times higher than that of the $\mathrm{PVDF} / \mathrm{BaTiO}_{3} 80 / 20$ nanocomposite. Finally, the electrical behavior of nanographite doped PVDF/ $\mathrm{BaTiO}_{3}$ composites can be well interpreted using the percolation theory. In addition, the dielectric constant and conductivity of the composites were strongly dependent on temperature.

\section{References}

[1] Venkatragavaraj E., Satish B., Vinod P. R., Vijaya M. S.: Piezoelectric properties of ferroelectric PZT-polymer composites. Journal of Physics D: Applied Physics, 34, 487-492 (2001).

DOI: $10.1088 / 0022-3727 / 34 / 4 / 308$

[2] Dang Z-M., Zheng Y., Xu H-P.: Effect of the ceramic particle size on the microstructure and dielectric properties of barium titanate/polystyrene composites. Journal of Applied Polymer Science, 110, 3473-3479 (2008). DOI: $10.1002 /$ app. 28856

[3] Ramajo L., Castro M. S., Reboredo M. M.: Effect of silane as coupling agent on the dielectric properties of $\mathrm{BaTiO}_{3}$-epoxy composites. Composites Part A: Applied Science and Manufacturing, 38, 1852-1859 (2007). DOI: 10.1016/j.compositesa.2007.04.003

[4] Arit G., Hennings D., de With G.: Dielectric properties of fine-grained barium titanate ceramics. Journal of Applied Physics, 58, 1619-1625 (1985).

DOI: $10.1063 / 1.336051$
[5] Xie S-H., Zhu B-K., Wei X-Z., Xu Z-K., Xu Y-Y.: Polyimide/ $/ \mathrm{BaTiO}_{3}$ composites with controllable dielectric properties. Composites Part A: Applied Science and Manufacturing, 36, 1152-1157 (2005).

DOI: $10.1016 /$ j.compositesa.2004.12.010

[6] Dang Z-M., Shen Y., Nan C-W.: Dielectric behavior of three-phase percolative $\mathrm{Ni}-\mathrm{BaTiO}_{3} /$ polyvinylidene fluoride composites. Applied Physics Letters, 81, 4814-4816 (2002).

DOI: $10.1063 / 1.1529085$

[7] Tchmutin I. A., Ponomarenko A. T., Shevchenko V. G., Ryvkina N. G., Klason C., Mcqueen D. H.: Electrical transport in 0-3 epoxy resin-barium titanate-carbon black polymer composites. Journal of Polymer Science Part B: Polymer Physics, 36, 1847-1856 (1998). DOI: $10.1002 /($ SICI) 1099-0488(199808)36:11<1847:: AID-POLB6 $>3.0 . C O ; 2-\mathrm{N}$

[8] Zhang C., Sheng J. F., Ma C. A., Sumita M.: Electrical and damping behaviors of $\mathrm{CPE} / \mathrm{BaTiO}_{3} / \mathrm{VGCF}$ composites. Materials Letters, 59, 3648-3651 (2005).

DOI: $10.1016 /$ j.matlet.2005.07.004

[9] Chen G., Weng W., Wu D., Wu C., Lu J., Wang P., Chen X.: Preparation and characterization of graphite nanosheets from ultrasonic powdering technique. Carbon, 42, 753-759 (2004).

DOI: 10.1016/j.carbon.2003.12.074

[10] Kulek J., Szafraniak I., Hilczer B., Połomska M.: Dielectric and pyroelectric response of PVDF loaded with $\mathrm{BaTiO}_{3}$ obtained by mechanosynthesis. Journal of Non-Crystalline Solids, 353, 4448-4452 (2007). DOI: $10.1016 /$ j.jnoncrysol.2007.02.077

[11] Cheng K-C., Lin C-M., Wang S-F., Lin S-T., Yang CF.: Dielectric properties of epoxy resin-barium titanate composites at high frequency. Materials Letters, 61, 757-760 (2007).

DOI: $10.1016 /$ j.matlet.2006.05.061

[12] Dang Z-M., Wang Y-H., Peng B., Nan C-W.: Effect of $\mathrm{BaTiO}_{3}$ size on dielectric property of $\mathrm{BaTiO}_{3} / \mathrm{PVDF}$ composites. Journal of Electroceramics, 21, 381-384 (2008). DOI: $10.1007 / \mathrm{s} 10832-007-9201-8$

[13] Dou X., Liu X., Zhang Y., Feng H., Chen J-F., Du S.: Improved dielectric strength of barium titanatepolyvinylidene fluoride nanocomposite. Applied Physics Letters, 95, 132904(1)-132904(3) (2009). DOI: $10.1063 / 1.3242004$

[14] Dang Z-M., Wang H-Y., Zhang Y-H., Qi J-Q.: Morphology and dielectric property of homogenous $\mathrm{BaTiO}_{3} / \mathrm{PVDF}$ nanocomposites prepared via the natural adsorption action of nanosized $\mathrm{BaTiO}_{3}$. Macromolecular Rapid Communications, 26, 1185-1189 (2005). DOI: $10.1002 /$ marc.200500137 
[15] Schumacher B., Geßwein H., Haußelt J., Hanemann T.: Temperature treatment of nano-scaled barium titanate filler to improve the dielectric properties of high-k polymer based composites. Microelectronic Engineering, 87, 1978-1983 (2010).

DOI: $10.1016 /$ j.mee.2009.12.018

[16] Huang C., Zhang Q.: Enhanced dielectric and electromechanical responses in high dielectric constant allpolymer percolative composites. Advanced Functional Materials, 14, 501-506 (2004).

DOI: $10.1002 / \mathrm{adfm} .200305021$
[17] Bergman D. J., Imry Y.: Critical behavior of the complex dielectric constant near the percolation threshold of a heterogeneous material. Physical Review Letters, 39, 1222-1225 (1977).

DOI: 10.1103/PhysRevLett.39.1222

[18] Dang Z-M., Yan W-T., Xu H-P.: Novel high-dielectricpermittivity poly(vinylidene fluoride)/polypropylene blend composites: The influence of the poly(vinylidene fluoride) concentration and compatibilizer. Journal of Applied Polymer Science, 105, 3649-3655 (2007).

DOI: 10.1002/app.26447 